\title{
Surface and Interacellular Targets of Acute Myeloid Leukemia Therapy Detectable at Leukemic Stem Cell level
}

\section{Adhra Al-Mawali* \\ Director of Centre of Studies \& Research, Ministry of Health, Oman}

*Corresponding author: Adhra Al-Mawali, Director of Centre of Studies \& Research, Ministry of Health, Muscat, Sultanate of Oman, P.O.Box 393, PC 113 Muscat-Oman, Tel:+968 24697551; Fax: +968 24696702; Email: adhra.almawali@gmail.com

\section{Review Article}

Volume 2 Issue 1

Received Date: February 01, 2018

Published Date: February 14, 2018

DOI: $10.23880 / \mathrm{hij}-16000116$

\section{Abstract}

For over 50 years investigators have considered a malignant stem cell as the potential origin of and a key therapeutic target for acute myeloid leukaemia (AML) and other forms of cancer. Leukaemic stem cells (LSCs) have been identified in acute myeloid leukaemia (AML). Similar to haemopoietic stem cells, these LSCs are able to self-renew, differentiate, and proliferate extensively. Recent studies suggest that LSCs are critical for the initiation and maintenance of leukaemia. Exciting new insights into the fundamental underpinnings of LSCs are now being made in an era in which drug development pipelines offer the potential to specifically target pathways of significance.

This mini review will describe the possible targets expressed on the surface of AML, the intracellular targets and the novel molecular and flow cytometry methodologies being used to particularly ablate the LSC population.

Keywords: Acute Myeloid Leukemia; Leukemic stem cell; Malignant stem cell

Abbreviations: AML: Acute Myeloid Leukaemia; LSCs: Leukaemic Stem Cells; AB: Antibiodies; BM: Bone Marrow; SIRPa: Signal Regulatory Protein; ADCC: Antibody Dependent Cell-mediated Cytotoxicity; ScFv: Single Chain Fragment of the Variable Regions; RTK: Receptor Tyrosine Kinases

\section{Targets of AML Therapy Detectable in Leukaemic Stem Cells}

Molecular constructions in AML cells that may serve as targets of specific therapy are located in various compartments of the leukaemic cell. Generally, such targets are either detectable on the cell surface or within the cytoplasm $[1,2]$.

\section{Targets Expressed on the Surface of AML Cells}

Based on target molecules expressed on the surface of leukaemic cells, a number of new treatment strategies have recently been established [3-8]. One of these concepts employs humanized antibodies (Ab) conjugated with a cytostatic drug. These conjugates bind to leukaemic cells through an interaction of the Ab with the target structure on the surface of AML blasts. 
Consecutively, the Ab-drug conjugate is internalized by the leukaemic cells. After internalization, the drug is released from the $\mathrm{Ab}$ and inhibits critical cell functions (depending on the nature of the cytostatic drug) and eventually leads to cell death $[5,6,9,10]$.

An important example for such conjugates is Mylotarg (gemtuzumab/ozogamicin), which consists of a humanized anti-Siglec-3 Ab (CD33) and the highly potent (toxic) cytostatic drug calicheamicin $[5,6,9,11]$. However, it has been found that patients are prone to relapse despite being effective at inducing remission in some patients, which raises the question of the resistance of LSCs to the toxin [12].

Another treatment concept for surface antigen targeted anti-leukaemic therapy is based on conjugates consisting of (humanized) antibodies and radio-isotopes [8,13-15]. One example is 131I-anti-CD45 [13,14,16]. However, it remains unclear whether this therapy will result in an improvement in the disease-free survival of patients with AML.

Furthermore, anti-interleukin-3 (IL-3) receptor alpha chain (CD123)-neutralizing antibody (7G3) targeted AML-LSCs, impairing homing to bone marrow (BM) and activating innate immunity of NOD/SCID mice. 7G3 treatment profoundly reduced AML-LSC engraftment and improved mouse survival. Mice with pre-established disease showed reduced AML burden in the BM and periphery and impaired secondary transplantation upon treatment, establishing that AML-LSCs were directly targeted. 7G3 inhibited IL-3-mediated intracellular signaling of isolated AML CD34 (+) CD38 (-) cells in vitro and reduced their survival. These results provide clear validation for therapeutic MoAbs targeting of AML-LSCs and for translation of in vivo preclinical research findings toward a clinical application [17].

CD47 (cytokine receptor like CD123), a transmembrane protein that serves as a ligand for signal regulatory protein (SIRP $\alpha$ ), is upregulated on AML LSCs than on HSCs. An increased expression of CD47 on LSC contributed to pathogenesis by inhibiting phagocytosis though the interaction of the CD47 with an inhibitory receptor on phagocytes. Thus, increased CD47 expression proved to be an independent poor prognostic factor. Targeting of human AML stem cells by blocking MoAbs directed against CD47 preferentially enabled phagocytosis of AML LSC. Elimination of human cancer cells in xenograft models of AML by this targeting method was also shown. The level of expression of CD47 on AML blasts is also associated with poor prognosis $[18,19]$.
CD96, a member of the Ig gene superfamily, has been shown to be expressed in a majority of the LSC population and at a much lower frequency in HSC's. CD96+ AML cells are highly enriched for LSC activity compared to CD96- AML cells. The presence of CD96 expression allows AML-LSC can be distinguished from normal HSC. Thus, CD96 is a cell surface marker which can serve as an LSC-specific therapeutic target [20].

Also recently, it was shown that CD96-specific antibodies can efficiently activate ADCC (Antibody dependent cell-mediated cytotoxicity) which is an important $\mathrm{Fc}$ receptor mediated effector mechanism for the in vivo activity of therapeutic antibodies. However, in a clinical setting, future studies are yet to determine whether or not the single chain fragment of the variable regions fusion proteins (scFv-based mini-antibodies) will be able to eradicate AML LSCs [21].

((for info on CD96 by Hosen et al 2007 [22]: i) Two clones, clone G8.5 and clone TH-111 were used to analyse CD96 expression in normal adult HSCs and progenitor cells by flow cytometry. Only $\approx 5 \%$ of BM cells in HSC-enriched region (Lin-CD34+CD38-CD90+) expressed CD96 weakly. ii) In $\approx 66 \%$ of samples, the percentage of CD96-positive cells in the CD34+CD38AML-LSC-enriched fraction was significantly higher than in normal human BM CD34+CD38- cells. CD96 is expressed almost exclusively in the CD90- subset. Thus, CD96 is frequently expressed on

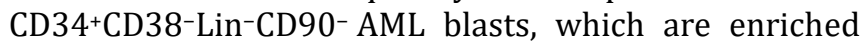
for LSC activity and exclude HSC. iii) FACS was used to fractionate human AML specimens into CD96+ and CD96populations and then transplanted into mice. CD96+ AML cells uniquely showed engraftment of human CD45 positive cells. The confirmation that the engrafted hCD45+ were human myeloid leukemia blasts was done by measuring CD13/CD14/CD33 expression and/or Wright-Giemsa stain of peripheral blood or BM cells. >> demonstrate that CD96 is expressed on functional LSC in human AML.)).

((for info on CD96 from Nodehi S, et al. [21]: Strategies are being developed to increase the antitumor efficacy of monoclonal antibodies by enhancing ADCC activity. Binding affinity to the target antigen as well as Fc binding to activating Fc-receptors has been identified as critical parameters for the ADCC activity of monoclonal antibodies. Single chain fragment of the variable regions (ScFv) -Fc fusion proteins (mini-antibodies) may represent one promising new molecule format)). 
CD32 and CD25 are cell surface markers which were found to be highly expressed in human AML LSCs and not expressed in normal HSCs. They were also found to be present in the all-important cell cycle-quiescent, AML initiating cells in the endosteal niche that might be the cause for AML relapse. This could facilitate the development of therapeutic strategies in AML because they were present in a significant number AML patients, especially the poor-risk population [23].

CXC chemokine receptor (CXCR4) which is a cell membrane receptor is found on stem cells [24-26]. It has been found that SDF-1 $\alpha$ (stromal cell-derived factor-1) /CXCR4 interactions contribute to the resistance of LSCs to apoptosis in the microenvironment. Effective targeting of CXCR4 and its interactions paves the way to eliminate and target cells that are usually protected by the bone marrow microenvironment [27].

Very recently, it was suggested that CXCR4 expression is associated with poor prognosis in AML patients and a marker of more aggressive disease in a normal karyotype AML population [28]. This can even be incorporated into risk assessment of AML patients [28,29]. In addition, cycling LSC population, characterized by CD93 expression (which is a marker for non- quiescent LSC population), have been shown in AML with an MLL gene rearrangement [30].

\section{Intracellular Targets of AML Therapy}

Over the past few years, a large number of cytoplasmic and nuclear target structures in AML cells have been identified [13,31-33]. Among these are DNA-methylating enzymes, histone deacetylases, leukaemia-specific fusion gene-products (such as PML/RAR $\alpha$ ), pro-oncogenic transcription factors (STAT-family, Ets, c-Myb, HOX, $\mathrm{NF} \kappa \mathrm{B}$, others) and critical elements in pro-oncogenic signal transduction cascades (RTKs, mutated oncogenic forms of Ras, others) [33].

Recent reports suggest that nuclear factor $\kappa B(N F-\kappa B)$ is constitutively expressed in blast cells in a majority of patients with AML [13,34-36]. Additionally, NF- $\mathrm{kB}-$ activity is detectable in the (quiescent) LSC population in these patients, whereas normal unstimulated HSC do not express NF- $\mathrm{kB}$ activity $[13,35]$. Thus, trying to eradicate LSC's by direct targeting using NF-kB pathway could be a potential therapeutic strategy.

A number of different tyrosine kinase inhibitors have recently been identified and applied in clinical trials in leukaemic patients [37-48]. Important stem cell receptor tyrosine kinases (RTK) expressed in AML cells are the SCF receptor KIT, M-CSF receptor FMS, PDGFR $\beta$, FLT1 and FLT3 $[33,47,49,50]$. At least some of these tyrosine kinases are also expressed in LSC [37]. Several previous and more recent observations suggest that these molecules do play an important role in leukaemogenesis $[33,47,49,51,52]$. Similarly, the FLT3 gene is the most frequently mutated gene in patients with AML $[33,49,50,52,53]$. These mutations lead to ligandindependent dimerisation of the receptor and its autophosphorylation with consecutive activation of multiple signal transduction pathways including the STAT5-, RAS/MAPK- and PI3K/AKT-pathway [54]. Since these mutations apparently act pro-oncogenically, it is appealing to speculate that they all take place and are detectable at the stem cell level in patients with AML.

A number of drugs targeting RTKs have recently been applied to AML cells in clinical and/or pre-clinical trials. Likewise, the inhibition of FLT3 by AG1296 or Herbimycin A in AML cells in mice was found to counteract the progression of leukaemia [33,49]. In addition, a number of targeting drugs directed against RTKs have been developed in recent years, including CEP701, CEP751, SU5614, SU5416, SU11248 and PKC412 $[37,42-48,55]$. These inhibitors may act on several RTKs including FLT3, thus inhibiting proliferation of leukaemic cells. Additionally, some of these inhibitors have already been evaluated in vivo. Likewise, CEP701 has been reported to induce responses in AML patients refractory to conventional chemotherapy [45]. Interestingly, at least some of these RTK-type receptors are known to be expressed in LSC.

A novel and promising therapeutic strategy to preferentially target human AML cells was uncovered by lysosome disruption. An important finding of this study was that AML LSCs were found to be enriched in bulk AML cells and their subsets which showed increased lysosomal size and biogenesis after lysosome disruption in human AML cells. This research study goes to show that some common biological features and mechanisms remain open to selective targeting even though AML biology is so widely known as heterogeneous [56].

Aurora A kinases are a family of mitotic serine/threonine kinases that play a role in cytokinesis during mitosis and cell division. AurA showed a significant higher level of expression in AML LSCs than in HSCs and can be used as a marker. The study showed that specific AurA inhibitors could be used to reduce LSCs. The study also further found that the reduction of 
LSC could be enhanced with stimulation with G-CSF and the use of AurA inhibitors [57].

Mcl-1 has been found to be up-regulated during AML relapses in FLT3/ITD AML LSCs (probably due to the fact that Mcl-1 confers some sort of resistance to chemotherapy) [58]. Furthermore, deletion of Mcl-1 led to induced death of transformed AML and eradicated disease in the AML NOD/SCID mice [59]. So, the lowering of Mcl-1 through a variety of approaches such as disruption or degradation of Mcl-1 by Bcl-2 inhibitors and other inhibitors and interfering with transcription and translation processes makes Mcl-1 a favourable therapeutic target in AML. The same study suggests that combination approaches which disrupt multiple prosurvival pathways and activate their pro-apoptotic pathways could show promise for targeting [60].

Inhibition of the PI3K-Akt-mTOR pathway seems to be a therapeutic strategy in human AML. Ryningen, et al. suggests that a combined targeting of different stages in the pathway could be investigated as a possible therapeutic strategy [61].

A recent report showed that AML cells rely on a tumor-specific heat shock protein species (teHsp90) that is selectively activated under conditions of cell stress and signalosome activity [62]. Additionally, a central component of stress response pathways, activation of NF-kB, is evident in LSCs, but not in normal resting HSCs [63]. Challenge of LSCs with agents that inhibit NF-kB, proteasome activity, HSP function, and glutathione balance have all been demonstrated to selectively target leukemic stem/progenitor cells in comparison to normal HSC controls $[13,64,65]$.

A recent study indicates that the physical transfer of mitochondria from mesenchymal cells can influence leukemic cells, making them more resistant to chemotherapy, a phenomenon also described for ovarian cancer cells $[66,67]$. Collectively, these findings indicate that modulation of niche interactions may serve to increase the sensitivity of LSCs to therapeutic intervention.

Finally, there is also evidence that a pro-inflammatory state can influence LSC growth/survival. An intriguing study by Kagoya, et al. has recently shown that autocrine secretion of TNF-alpha drives the constitutive activation of NF-kB, a property of LSCs that is presumably associated with their intrinsic biology and malignant transformation [63]. Further, a number of mutations associated with myeloid malignancy and stem cell transformation support a pro-inflammatory milieu that likely favors growth of LSCs [68]. Conversely, chronic inflammation has been shown to degrade the potential of normal HSC $[69,70]$. Hence, inhibition of proinflammatory factors may serve the dual function of inhibiting LSC activity and creating an environment more favorable for normal stem cells. This type of intervention could be particularly interesting in the context of post chemotherapy treatment, where the need for suppression of residual disease and promotion of normal cell regeneration is perhaps most acute.

\section{Summary and Future Directions}

AML populations are consisted of hierarchical structure and in recent years it has been possible to begin analyzing individual constituents of the leukaemic clone. Although, varying AML subtypes differentiate to differing levels, it has become increasingly evident that important similarities exit at the top of the developmental hierarchy.

Given the quiescent status of LSCs and their relatively low frequency, ablation of this population is likely to be a significant challenge. Despite the fact that a variety of LSC characteristics are almost identical to normal HSCs, recent studies of AML molecular biology suggest that some differences between normal and leukaemic cells are apparent in the stem cell/progenitor cell pool [71]. From a therapeutic perspective, this observation is extremely important because it suggests LSCs do have unique characteristics that may make them preferentially sensitive to apoptosis /ablation. This information also serves to emphasize the importance of better understanding LSCs and how they differ from normal HSCs.

By establishing general parameters for induction of LSC apoptosis, it should be potential to develop more effective clinical therapies. Given the heterogeneity of mutations that give rise to these malignancies, the ability to target the malignant population is not likely to be achieved by a single specific inhibitor. To this end, it is fundamental to completely understand the signaling pathways that regulate survival and death in LSC populations. Current studies have started to characterize molecular mechanisms that may be relevant to LSC survival. However, more comprehensive methodologies using multiparameter or combined approaches should be the priority for future studies [72-74]. Well-designed studies incorporating elements such as randomized discontinuation [75], as has been done in other oncology studies [76], may be required to answer these questions. 
We look forward to the day when these questions become relevant in the drug development process for AML, and have reason to hope that they are around the corner.

\section{References}

1. Jordan CT, Guzman ML, Noble M (2006) Cancer stem cells. New England Journal of Medicine 355(12): 1253-1261.

2. Valent P, Cerny-Reiterer S, Herrmann H, Mirkina I, George TI, et al. (2010) Phenotypic heterogeneity, novel diagnostic markers, and target expression profiles in normal and neoplastic human mast cells. Best Pract Res Clin Haematol 23(3): 369-378.

3. Treish IM (2000) Targeting leukemia cells with gemtuzumab ozogamicin. Cancer Pract 8(5): 254256.

4. Krauth MT, Bohm A, Agis H, Sonneck K, Samorapoompichit P, Florian S, et al. (2007) Effects of the CD33-targeted drug gemtuzumab ozogamicin (Mylotarg) on growth and mediator secretion in human mast cells and blood basophils. Exp Hematol 35(1): 108-116.

5. Hamann PR, Hinman LM, Beyer CF, Lindh D, Upeslacis J, et al. (2002) An anti-CD33 antibodycalicheamicin conjugate for treatment of acute myeloid leukemia Choice of linker. Bioconjug Chem 13(1): 40-46.

6. Hamann PR, Hinman LM, Hollander I, Beyer CF, Lindh D, et al. (2002) Gemtuzumab ozogamicin, a potent and selective anti-CD33 antibodycalicheamicin conjugate for treatment of acute myeloid leukemia. Bioconjug Chem 13(1): 47-58.

7. Matthews DC, Appelbaum FR, Eary JF, Fisher DR, Durack LD, et al. (1999) Phase I study of (131)I-antiCD45 antibody plus cyclophosphamide and total body irradiation for advanced acute leukemia and myelodysplastic syndrome. Blood 94(4): 1237-1247.

8. Matthews DC, Martin PJ, Nourigat C, Appelbaum FR, Fisher DR, et al. (1999) Marrow ablative and immunosuppressive effects of 131I-anti-CD45 antibody in congenic and $\mathrm{H} 2$-mismatched murine transplant models. Blood 93(2): 737-745.

9. Sievers EL (2001) Efficacy and safety of gemtuzumab ozogamicin in patients with CD33-positive acute myeloid leukaemia in first relapse. Expert Opin Biol Ther 1(5): 893-901.

10. Kletting P, Kull T, Bunjes D, Mahren B, Luster M, et al. (2010) Radioimmunotherapy with anti-CD66 antibody: improving the biodistribution using a physiologically based pharmacokinetic model. J Nucl Med 51(3): 484-491.

11. Fernandez HF, Rowe JM (2010) Induction therapy in acute myeloid leukemia: intensifying and targeting the approach. Curr Opin Hematol 17(2): 79-84.

12. Linenberger ML, Hong T, Flowers D, Sievers EL, Gooley TA, et al. (2001) Multidrug-resistance phenotype and clinical responses to gemtuzumab ozogamicin. Blood 98(4): 988-994.

13. Guzman ML, Swiderski CF, Howard DS, Grimes BA, Rossi RM, et al. (2002) Preferential induction of apoptosis for primary human leukemic stem cells. Proc Natl Acad Sci USA 99(25): 16220-16225.

14. Pagel JM, Matthews DC, Appelbaum FR, Bernstein ID, Press OW (2002) The use of radioimmunoconjugates in stem cell transplantation. Bone Marrow Transplant 29(10): 807-816.

15. Terpstra W, Rozemuller H, Breems DA, Rombouts EJ, Prins A, et al. (1997) Diphtheria toxin fused to granulocyte-macrophage colony-stimulating factor eliminates acute myeloid leukemia cells with the potential to initiate leukemia in immunodeficient mice, but spares normal hemopoietic stem cells. Blood 90(9): 3735-3742.

16. Kletting P, Bunjes D, Reske SN, Glatting G (2009) Improving anti-CD45 antibody radioimmunotherapy using a physiologically based pharmacokinetic model. J Nucl Med 50(2): 296-302.

17. Jin L, Lee EM, Ramshaw HS, Busfield SJ, Peoppl AG, et al. (2009) Monoclonal antibody-mediated targeting of CD123, IL-3 receptor alpha chain, eliminates human acute myeloid leukemic stem cells. Cell Stem Cell 5(1): 31-42.

18. Majeti R, Chao MP, Alizadeh AA, Pang WW, Jaiswal S, et al. (2009) CD47 is an adverse prognostic factor and therapeutic antibody target on human acute myeloid leukemia stem cells. Cell 138(2): 286-299.

19. Theocharides AP, Jin L, Cheng PY, Prasolava TK, Malko AV, et al. (2012) Disruption of SIRP $\alpha$ signaling 
in macrophages eliminates human acute myeloid leukemia stem cells in xenografts. J Exp Med 209(10): 1883-1899.

20. Hosen N, Park CY, Tatsumi N, Oji Y, Sugiyama H, et al. (2007) CD96 is a leukemic stem cell-specific marker in human acute myeloid leukemia. Proc Natl Acad Sci USA 104(26): 11008-11013.

21. Nodehi SM, Repp R, Kellner C, Bräutigam J, Staudinger M, et al. (2012) Enhanced ADCC activity of affinity maturated and Fc-engineered miniantibodies directed against the AML stem cell antigen CD96. PLoS One 7(8): e42426.

22. Hosen N, Park CY, Tatsumi N, Oji Y, Sugiyama H, et al. (2007) CD96 is a leukemic stem cell-specific marker in human acute myeloid leukemia. Proc Natl Acad Sci USA 104(26): 11008-11013.

23. Saito Y, Kitamura H, Hijikata A, Tomizawa-Murasawa M, Tanaka S, et al. (2010) Identification of therapeutic targets for quiescent, chemotherapyresistant human leukemia stem cells. Sci Transl Med 2(17): 17ra9.

24. Möhle R, Bautz F, Rafii S, Moore MAS, Brugger W (1998) The Chemokine Receptor CXCR-4 Is Expressed on CD34+Hematopoietic Progenitors and Leukemic Cells and Mediates Transendothelial Migration Induced by Stromal Cell-Derived Factor-1. Blood 91(12): 4523-4530.

25. Möhle R, Schittenhelm M, Failenschmid C, Bautz F, Kratz-Albers K, et al. (2000) Functional response of leukaemic blasts to stromal cell-derived factor-1 correlates with preferential expression of the chemokine receptor CXCR4 in acute myelomonocytic and lymphoblastic leukaemia. Br J Haematol 110(3): 563-572.

26. Voermans C, Van Heese W, De Jong I, Gerritsen W, van Der Schoot C (2002) Migratory behavior of leukemic cells from acute myeloid leukemia patients. Leukemia 16(4): 650-657.

27. Zeng Z, Xi Shi Y, Samudio IJ, Wang RY, Ling X, et al. (2009) Targeting the leukemia microenvironment by CXCR4 inhibition overcomes resistance to kinase inhibitors and chemotherapy in AML. Blood 113(24): 6215-6224.

28. Ahn JY, Seo K, Weinberg OK, Arber DA (2013) The Prognostic Value of CXCR4 in Acute Myeloid
Leukemia. Appl Immunohistochem Mol Morphol 21(1): 79-84.

29. Spoo AC, Lübbert M, Wierda WG, Burger JA (2007) CXCR4 is a prognostic marker in acute myelogenous leukemia. Blood 109(2): 786-791.

30. Iwasaki M, Liedtke M, Gentles AJ, Cleary ML (2015) CD93 marks a non-quiescent human leukemia stem cell population and is required for development of MLL-rearranged acute myeloid leukemia. Cell Stem Cell 17(4): 412-421.

31. Stirewalt DL, Meshinchi S, Radich JP (2003) Molecular targets in acute myelogenous leukemia. Blood Rev 17(1): 15-23.

32. Dash A, Gilliland DG (2001) Molecular genetics of acute myeloid leukaemia. Best Pract Res Clin Haematol 14(1): 49-64.

33. Gilliland DG, Jordan CT, Felix CA (2004) The molecular basis of leukemia. Hematology Am Soc Hematol Educ Program 2004: 80-97.

34. Guzman ML, Jordan CT (2004) Considerations for targeting malignant stem cells in leukemia. Cancer Control 11(2): 97-104.

35. Guzman ML, Neering SJ, Upchurch D, Grimes B, Howard DS, et al. (2001) Nuclear factor-kappaB is constitutively activated in primitive human acute myelogenous leukemia cells. Blood 98(8): 23012307.

36. Ebihara Y, Wada M, Ueda T, Xu MJ, Manabe A, et al. (2002) Reconstitution of human haematopoiesis in non-obese diabetic/severe combined immunodeficient mice by clonal cells expanded from single CD34+CD38- cells expressing Flk2/Flt3. Br J Haematol 119(2): 525-534.

37. Druker BJ, O'Brien SG, Cortes J, Radich J (2002) Chronic myelogenous leukemia. Hematology Am Soc Hematol Educ Program 2002: 111-135.

38. Ruggeri BA, Miknyoczki SJ, Singh J, Hudkins RL (1999) Role of neurotrophin-trk interactions in oncology: the anti-tumor efficacy of potent and selective trk tyrosine kinase inhibitors in pre-clinical tumor models. Curr Med Chem 6(9): 845-857.

39. Zheng R, Friedman AD, Small D (2002) Targeted inhibition of FLT3 overcomes the block to myeloid 
differentiation in 32Dcl3 cells caused by expression of FLT3/ITD mutations. Blood 100(12): 4154-4161.

40. Levis M, Allebach J, Tse KF, Zheng R, Baldwin BR, et al. (2002) A FLT3-targeted tyrosine kinase inhibitor is cytotoxic to leukemia cells in vitro and in vivo. Blood 99(11): 3885-3891.

41. Spiekermann K, Dirschinger RJ, Schwab R, Bagrintseva K, Faber F, et al. (2003) The protein tyrosine kinase inhibitor SU5614 inhibits FLT3 and induces growth arrest and apoptosis in AML-derived cell lines expressing a constitutively activated FLT3. Blood 101(4): 1494-1504.

42. O'Farrell AM, Abrams TJ, Yuen HA, Ngai TJ, Louie SG, et al. (2003) SU11248 is a novel FLT3 tyrosine kinase inhibitor with potent activity in vitro and in vivo. Blood 101(9): 3597-3605.

43. Weisberg E, Boulton C, Kelly LM, Manley P, Fabbro D, et al. (2002) Inhibition of mutant FLT3 receptors in leukemia cells by the small molecule tyrosine kinase inhibitor PKC412. Cancer Cell 1(5): 433-443.

44. Smith BD, Levis M, Beran M, Giles F, Kantarjian H, et al. (2004) Single-agent CEP-701, a novel FLT3 inhibitor, shows biologic and clinical activity in patients with relapsed or refractory acute myeloid leukemia. Blood 103(10): 3669-3676.

45. O'Farrell AM, Foran JM, Fiedler W, Serve H, Paquette RL, et al. (2003) An innovative phase I clinical study demonstrates inhibition of FLT3 phosphorylation by SU11248 in acute myeloid leukemia patients. Clin Cancer Res 9(15): 5465-5476.

46. Reilly JT (2002) Class III receptor tyrosine kinases: role in leukaemogenesis. Br J Haematol 116(4): 744757.

47. Karp JE, Lancet JE, Kaufmann SH, End DW, Wright JJ, et al. (2001) Clinical and biologic activity of the farnesyltransferase inhibitor R115777 in adults with refractory and relapsed acute leukemias: a phase 1 clinical-laboratory correlative trial. Blood 97(11): 3361-3369.

48. Gilliland DG, Griffin JD (2002) Role of FLT3 in leukemia. Curr Opin Hematol 9(4): 274-281.

49. Weisberg E, Barrett R, Liu Q, Stone R, Gray N, et al. (2009) FLT3 inhibition and mechanisms of drug resistance in mutant FLT3-positive AML. Drug Resist Updat 12(3): 81-89.

50. Galimberti S, Guerrini F, Carulli G, Fazzi R, Palumbo GA, et al. (2004) Significant co-expression of WT1 and MDR1 genes in acute myeloid leukemia patients at diagnosis. Eur J Haematol 72(1): 45-51.

51. Gilliland DG, Griffin JD (2002) The roles of FLT3 in hematopoiesis and leukemia. Blood 100(5): 15321542.

52. Kelly LM, Liu Q, Kutok JL, Williams IR, Boulton CL, et al. (2002) FLT3 internal tandem duplication mutations associated with human acute myeloid leukemias induce myeloproliferative disease in a murine bone marrow transplant model. Blood 99(1): 310-318.

53. Orlowski RZ, Stinchcombe TE, Mitchell BS, Shea TC, Baldwin AS, et al. (2002) Phase I trial of the proteasome inhibitor PS-341 in patients with refractory hematologic malignancies. J Clin Oncol 20(22): 4420-4427.

54. Mesters RM, Padro T, Bieker R, Steins M, Kreuter M, et al. (2001) Stable remission after administration of the receptor tyrosine kinase inhibitor SU5416 in a patient with refractory acute myeloid leukemia. Blood 98(1): 241-243.

55. Sukhai MA, Prabha S, Hurren R, Rutledge AC, Lee AY, et al. (2013) Lysosomal disruption preferentially targets acute myeloid leukemia cells and progenitors. J Clin Invest 123(1): 315-328.

56. Kim SJ, Jang JE, Cheong JW, Eom JI, Jeung HK, et al. (2012) Aurora A kinase expression is increased in leukemia stem cells, and a selective Aurora A kinase inhibitor enhances Ara-C-induced apoptosis in acute myeloid leukemia stem cells. Korean J Hematol 47(3): 178-185.

57. Kasper S, Breitenbuecher F, Heidel F, Hoffarth S, Markova B, et al. (2012) Targeting MCL-1 sensitizes FLT3-ITD-positive leukemias to cytotoxic therapies. Blood Cancer J 2(3): e60.

58. Glaser SP, Lee EF, Trounson E, Bouillet P, Wei A, et al. (2012) Anti-apoptotic Mcl-1 is essential for the development and sustained growth of acute myeloid leukemia. Genes dev 26(2): 120-125. 
59. Bose P, Grant S (2013) Mcl-1 as a therapeutic target in acute myelogenous leukemia (AML). Leuk Res Rep 2(1): 12-14.

60. Ryningen A, Reikvam H, Nepstad I, Paulsen Rye K, Bruserud $O$ (2012) Inhibition of Mammalian Target of Rapamycin in Human Acute Myeloid Leukemia Cells Has Diverse Effects That Depend on the Environmental In Vitro Stress. Bone Marrow Research 2012: 10.

61. Zong H, Gozman A, Caldas-Lopes E, Taldone T, Sturgill E, et al. (2015) A hyperactive signalosome in acute myeloid leukemia drives addiction to a tumorspecific Hsp90 species. Cell reports 13(10): 21592173.

62. Kagoya Y, Yoshimi A, Kataoka K, Nakagawa M, Kumano K, et al. (2014) Positive feedback between $N F-\kappa B$ and TNF- $\alpha$ promotes leukemia-initiating cell capacity. J Clin Invest 124(2): 528-542.

63. Guzman ML, Rossi RM, Karnischky L, Li X, Peterson $\mathrm{DR}$, et al. (2005) The sesquiterpene lactone parthenolide induces apoptosis of human acute myelogenous leukemia stem and progenitor cells. Blood 105(11): 4163-4169.

64. Pei S, Minhajuddin M, Callahan KP, Balys M, Ashton JM, et al. (2013) Targeting aberrant glutathione metabolism to eradicate human acute myelogenous leukemia cells. J Biol Chem 288(47): 33542-33558.

65. Nieman KM, Kenny HA, Penicka CV, Ladanyi A, BuellGutbrod R, et al. (2011) Adipocytes promote ovarian cancer metastasis and provide energy for rapid tumor growth. Nat Med 17(11): 1498-1503.

66. Moschoi R, Imbert V, Nebout M, Chiche J, Mary D, et al. (2016) Protective mitochondrial transfer from bone marrow stromal cells to acute myeloid leukemic cells during chemotherapy. Blood 128(2): 253-264.

67. Schepers K, Campbell TB, Passegué E (2015) Normal and leukemic stem cell niches: insights and therapeutic opportunities. Cell Stem Cell 16(3): 254267.
68. Pietras EM, Mirantes-Barbeito C, Fong S, Loeffler D, Kovtonyuk LV, et al. (2016) Chronic interleukin-1 exposure drives haematopoietic stem cells towards precocious myeloid differentiation at the expense of self-renewal. Nat Cell Biol 18(6): 607-618.

69. Mirantes C, Passegué E, Pietras EM (2014) Proinflammatory cytokines: emerging players regulating HSC function in normal and diseased hematopoiesis. Exp Cell Res 329(2): 248-254.

70. Al-Mawali A, Gillis D, Lewis I (2010) Immunoprofiling Of Acute Myeloid Leukemia Stem Cells With CD123 Marks FLT3/ITD Positive Clones. Cytometry B Clin Cytom 78(B): 406-459.

71. Al-Mawali A, Gillis D, Lewis I (2009) The role of multiparameter flow cytometry for detection of minimal residual disease in acute myeloid leukemia. Am J Clin Pathol 131(1): 16-26.

72. Al-Mawali A, Gillis D, Lewis I (2009) The use of receiver operating characteristic analysis for detection of minimal residual disease using fivecolor multiparameter flow cytometry in acute myeloid leukemia identifies patients with high risk of relapse. Cytometry B Clin Cytom 76(2): 91-101.

73. Grant S (2008) Is the focus moving toward a combination of targeted drugs? Best Pract Res Clin Haematol 21(4): 629-637.

74. Karrison TG, Ratain MJ, Stadler WM, Rosner GL (2012) Estimation of progression-free survival for all treated patients in the randomized discontinuation trial design. Am Stat 66(3): 155-162.

75. Ratain MJ, Eisen T, Stadler WM, Flaherty KT, Kaye SB, et al. (2006) Phase II placebo-controlled randomized discontinuation trial of sorafenib in patients with metastatic renal cell carcinoma. J Clin Oncol 24(16): 2505-2512.

76. Al-Mawali A (2013) Leukemic stem cells shows the way for novel target of acute myeloid leukemia therapy. J Stem Cell Res Ther 3(4): 151.

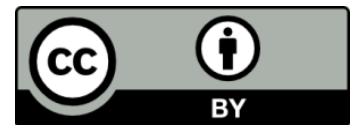

